\title{
Recent Advances in Understanding Mammalian Prion Structure: A Mini Review
}

\author{
Cassandra Terry ${ }^{1 *}$ and Jonathan D. F. Wadsworth ${ }^{2 *}$ \\ ${ }^{1}$ Molecular Systems for Health Research Group, School of Human Sciences, London Metropolitan University, London, \\ United Kingdom, ${ }^{2}$ MRC Prion Unit at UCL, UCL Institute of Prion Diseases, University College London, London, \\ United Kingdom
}

OPEN ACCESS

Edited by:

Tiago F. Outeiro,

University Medical Center

Goettingen, Germany

Reviewed by: Charles Robert Harrington, University of Aberdeen, United Kingdom Joern R. Steinert, University of Leicester, United Kingdom

*Correspondence: Cassandra Terry c.terry@/ondonmet.ac.uk Jonathan D. F. Wadsworth j.wadsworth@prion.ucl.ac.uk

Received: 12 April 2019 Accepted: 17 June 2019 Published: 09 July 2019

Citation: Terry $C$ and Wadsworth JDF (2019) Recent Advances in Understanding Mammalian Prion

Structure: A Mini Review.

Front. Mol. Neurosci. 12:169. doi: 10.3389/fnmol.2019.00169
Prions are lethal pathogens, which cause fatal neurodegenerative diseases in mammals. They are unique infectious agents and are composed of self-propagating multi-chain assemblies of misfolded host-encoded prion protein (PrP). Understanding prion structure is fundamental to understanding prion disease pathogenesis however to date, the high-resolution structure of authentic ex vivo infectious prions remains unknown. Advances in determining prion structure have been severely impeded by the difficulty in recovering relatively homogeneous prion particles from infected brain and definitively associating infectivity with the PrP assembly state. Recently, however, images of highly infectious ex vivo PrP rods that produce prion-strain specific disease phenotypes in mice have been obtained using cryo-electron microscopy and atomic force microscopy. These images have provided the most detailed description of ex vivo mammalian prions reported to date and have established that prions isolated from multiple strains have a common hierarchical structure. Misfolded PrP is assembled into $20 \mathrm{~nm}$ wide rods containing two fibers, each with double helical repeating substructure, separated by a characteristic central gap 8-10 nm in width. Irregularly structured material with adhesive properties distinct to that of the fibers is present within the central gap of the rod. Prions are clearly distinguishable from non-infectious recombinant PrP fibrils generated in vitro and from all other propagating protein structures so far described in other neurodegenerative diseases. The basic architecture of mammalian prions appears to be exceptional and fundamental to their lethal pathogenicity.

Keywords: Alzheimer's disease, prion disease, prion, prion-like, prion structure, amyloid beta, $\alpha$-synuclein, tau

\section{INTRODUCTION}

Prion diseases are a closely related group of neurodegenerative conditions which affect both humans and animals. They include bovine spongiform encephalopathy (BSE) in cattle, scrapie in sheep and goats, chronic wasting disease (CWD) in deer and elk, and the human prion diseases, kuru, Creutzfeldt-Jakob disease (CJD), variant CJD (vCJD), fatal familial insomnia (FFI) and Gerstmann-Sträussler-Scheinker disease (GSS; Prusiner, 1998; Collinge, 2001; Wadsworth and Collinge, 2011; Haïk and Brandel, 2014; Greenlee and Greenlee, 2015; Benestad and Telling, 2018; Rossi et al., 2019). They are exceptional pathogens (devoid of 
significant coding nucleic acid) and comprise infectious polymeric assemblies of misfolded host-encoded prion protein (PrP; Prusiner, 1998; Collinge and Clarke, 2007; Collinge, 2016). Prions propagate by means of seeded protein polymerization, which involves recruitment of $\operatorname{PrP}$ monomers to fibrillar assemblies followed by fragmentation of these structures to generate more "seeds." Different prion strains produce different disease phenotypes in the same inbred host and appear to be encoded by distinct misfolded PrP conformations and quaternary assembly states (Prusiner, 1998; Collinge and Clarke, 2007; Collinge, 2016).

While lacking the overt infectivity of prions, many other proteins are also capable of seeded protein misfolding and the generation of self-propagating polymeric or amyloid protein assemblies now appears to be widely involved in the pathogenesis of many other human diseases. Consequently "prion-like" mechanisms and the prion strain phenomena have become a major research focus in other neurodegenerative conditions, in particular, in Alzheimer's disease (AD) and Parkinson's disease where propagating assemblies of amyloid- $\beta$, tau and $\alpha$-synuclein are being studied (Prusiner, 2013; Goedert, 2015; Collinge, 2016; Walker, 2016; Qiang et al., 2017; Condello et al., 2018; Peng et al., 2018; Vaquer-Alicea and Diamond, 2019). Notably, in the case of tau, structurally distinct fibrillar assemblies from brain have recently been characterized in AD, Pick's disease and chronic traumatic encephalopathy (CTE) strongly suggesting that distinct strains of propagating tau assemblies are contributing to different disease phenotypes in humans (Fitzpatrick et al., 2017; Falcon et al., 2018; Falcon et al., 2019).

Significantly, while iatrogenic transmission of neurodegenerative diseases was thought to be restricted to prions, there is now considerable evidence for human transmission of cerebral amyloid angiopathy and amyloid- $\beta$ protein pathology resulting from discontinued medical practices involving treatment with human cadaveric pituitary-derived growth hormone or cadaveric dura mater grafting (Jaunmuktane et al., 2015; Frontzek et al., 2016; Ritchie et al., 2017; Cali et al., 2018; Purro et al., 2018; Banerjee et al., 2019). These findings now underscore the importance of fully understanding the prion-like properties of proteopathic seeds generated in other neurodegenerative diseases and systematically establishing their potential risks for iatrogenic transmission.

At present there is considerable debate regarding the nomenclature that should be used in describing the propagation of non-PrP protein assemblies (to distinguish them from lethal $\operatorname{PrP}$ prions) with terms such as propagons and prionoids being proposed (Collinge, 2016; Kara et al., 2018; Scheckel and Aguzzi, 2018; Duyckaerts et al., 2019; Eraña, 2019). Biological criteria that a propagating protein assembly must fulfill in order to be regarded as truly "prion-like" have yet to be defined (Kara et al., 2018; Scheckel and Aguzzi, 2018; Duyckaerts et al., 2019; Eraña, 2019) and structural classification of propagating protein assemblies remains a key goal. Indeed, in this context, it should be noted that propagation and spread of assemblies of amyloid- $\beta$, tau and $\alpha$-synuclein in animal models of other neurodegenerative diseases rarely result in lethal neurodegeneration, suggesting that the basic architecture of mammalian prions may be unique and central to their lethality (Collinge, 2016; Terry et al., 2019).

Here, we now highlight recent advances in prion isolation and structural characterization that have provided the first meaningful opportunity to compare the basic architecture of authentic infectious mammalian prions with the structures of protein assemblies from other neurodegenerative diseases. Current available data indicate that mammalian prions have unique structural features that readily distinguish them from propagating assemblies of amyloid- $\beta$, tau and $\alpha$-synuclein that have been described in other neurodegenerative diseases.

\section{KEY MOLECULAR FEATURES OF PRION DISEASES}

The central feature of prion diseases is the aberrant misfolding of PrP which can adopt distinct conformations and assembly states (Prusiner, 1998; Collinge and Clarke, 2007; Rodriguez et al., 2017). The normal form of the protein, referred to as $\mathrm{PrP}^{\mathrm{C}}$ (the cellular isoform) is a highly conserved cell surface glycosylphosphatidylinositol (GPI)-anchored sialoglycoprotein with an ordered C-terminal domain containing three $\alpha$-helices, a short anti-parallel $\beta$-sheet and a flexible disordered $\mathrm{N}$-terminal domain (Wüthrich and Riek, 2001; Rodriguez et al., 2017) and is soluble in detergents and sensitive to digestion with proteases. In contrast, disease-associated isoforms of PrP that comprise infectious prion assemblies are found only in prion-infected tissue and are composed of detergent-insoluble polymeric PrP structures some of which become protease-resistant and are classically termed $\operatorname{PrP}^{\mathrm{Sc}}$ (the scrapie isoform; Meyer et al., 1986; Prusiner, 1987, 1991, 1998). $\mathrm{PrP}^{\mathrm{Sc}}$ is derived from $\mathrm{PrP}^{\mathrm{C}}$ by conformational rearrangement and neither systematic study of known covalent post-translational modifications nor amino acid sequencing have shown any consistent variations between $\mathrm{PrP}^{\mathrm{Sc}}$ and $\operatorname{PrP}^{\mathrm{C}}$ (Prusiner, 1991, 1998; Riesner, 2003). The structural transition of $\mathrm{PrP}^{\mathrm{C}}$ to fibrillar assemblies of $\mathrm{PrP}^{\mathrm{Sc}}$ involves acquisition of a beta sheet rich configuration (Pan et al., 1993; Caughey et al., 1998; Prusiner, 1998; Riesner, 2003; Rodriguez et al., 2017) likely to be similar to amyloid where beta sheets stack perpendicular to the fiber axis forming a cross-beta structure (Eisenberg and Sawaya, 2017; Iadanza et al., 2018).

To date, the critical molecular events during infection that generate prototypical $\mathrm{PrP}^{\mathrm{Sc}}$ and how this causes neurodegeneration remains poorly defined. Notably, in many prion strain/host combinations the majority of disease-related $\mathrm{PrP}$ and prion titre is destroyed by protease-treatments that are typically used to detect prototypical $\mathrm{PrP}^{\mathrm{Sc}}$ (Safar et al., 1998, 2005; Cronier et al., 2008; D’Castro et al., 2010; Tixador et al., 2010; Sandberg et al., 2014). These findings indicate that the term $\mathrm{PrP}^{\mathrm{Sc}}$, often used interchangeably with prion infectivity, should be restricted to material as classically biochemically defined (infectious detergent-insoluble, protease-resistant $\mathrm{PrP}$ assemblies). Such prototypical $\mathrm{PrP}^{\mathrm{Sc}}$ comprises a small proportion of total disease-related $\mathrm{PrP}$ isoforms and while it is clearly an infectious structure its specific contribution to other aspects of disease pathogenesis remains unclear (Sandberg et al., 2014). Notably in this context, it is now thought 
that a distinct oligomeric or monomeric PrP isoform designated $\operatorname{PrP}^{L}$ (for lethal) may comprise the neurotoxic species, and that prototypical $\mathrm{PrP}^{\mathrm{Sc}}$ and indeed prions per se may not themselves be highly neurotoxic (Collinge and Clarke, 2007; Sandberg et al., 2011, 2014; Collinge, 2016). Determining the structural relationship between infectious and neurotoxic $\operatorname{PrP}$ species and whether protease-sensitive and protease-resistant infectious PrP assemblies are simply different-sized particles of essentially the same PrP structure has yet to be resolved. Consequently, it is now clear that a complete understanding of prion disease pathogenesis will require knowledge not only of infectious $\operatorname{PrP}$ structures but also the role of other PrP assemblies that may be variably generated during prion disease pathogenesis (Collinge and Clarke, 2007; Collinge, 2016).

\section{BRIEF OVERVIEW OF HISTORICAL STUDIES ON PRION STRUCTURE}

High resolution structural analysis of infectious mammalian prions has been obstructed by two central problems. First, the difficulty in recovering relatively homogeneous particles from affected tissue whose composition and PrP assembly state can be directly correlated with infectivity, and second, the failure to reproducibly generate high-titre synthetic prions from fully defined constituents. Although the formation of prions in vitro from recombinant $\operatorname{Pr} \mathrm{P}$ or isolated $\mathrm{PrP}^{\mathrm{C}}$ preparations (either alone or in combination with non-protein cofactors) has been reported, specific-infectivities are generally too low for meaningful structural analysis (Collinge and Clarke, 2007; DiazEspinoza and Soto, 2012; Schmidt et al., 2015; Collinge, 2016) and preparations with high prion titre (for example Moudjou et al., 2016) have not yet been structurally characterized. Consequently, the goal of solving infectious prion structure continues to rely upon the isolation of high-titre ex vivo prions in a form suitable for detailed structural study.

Scrapie associated fibrils (SAFs; Merz et al., 1981) and prion rods (Prusiner et al., 1983) were first described in prion-enriched isolates from infected brain tissue more than 35 years ago. While contemporary comparison of SAFs and prion rods now suggest they are synonymous, at the time of their discovery (before the PrP gene was identified) they were interpreted very differently. While Merz et al. (1984) proposed that SAFs may represent a new class of filamentous animal virus, Prusiner et al. (1983) proposed that prion rods were infectious protein assemblies (prions) composed of a protein designated PrP 27-30 (subsequently established to be proteolytically truncated $\operatorname{Pr} \mathrm{P}^{\mathrm{Sc}}$ ) and that the morphology of the prion rods was incompatible with a uniform virus structure (DeArmond et al., 1985); in particular, that the length of the prion rods was not essential for preservation of prion infectivity (Barry et al., 1985; Prusiner, 1987). Subsequently, Prusiner $(1991,1998)$ proposed that the prion rods were an artifact of purification and suggested that protease-truncation of $\operatorname{PrP}^{\mathrm{Sc}}$ to $\operatorname{PrP} 27-30$ in the presence of detergent facilitated the assembly of prion rods from smaller infectious oligomers of $\mathrm{PrP}^{\mathrm{Sc}}$ (McKinley et al., 1991). While this proposal at the time clearly excluded a viral etiology for prion diseases, this situation also left the field having to contend with the idea that large fibrillar PrP assemblies associated with prion infectivity might not actually represent authentic biologically relevant structures. Consequently, many researchers chose not to pursue structural characterization of the prion rods and instead focused on either trying to isolate smaller infectious oligomers of $\mathrm{PrP}^{\mathrm{Sc}}$ from infected brain or generating synthetic prions from bacterially expressed recombinant PrP. While numerous studies have now proposed various possible PrP structures as the authentic infectious prion assembly state (Silveira et al., 2005; Sim and Caughey, 2009; Wille et al., 2009; Requena and Wille, 2014; Vázquez-Fernández et al., 2016, 2017) none of these have been convincingly correlated with high specific prion infectivity and no international consensus has been reached on their in vivo relevance (Baskakov et al., 2019).

\section{RECENT PROGRESS IN PURIFYING AND CHARACTERIZING MAMMALIAN PRIONS}

The availability of cell-based prion bioassays (Klöhn et al., 2003; Mahal et al., 2007; Schmidt et al., 2015) has recently enabled the development of novel procedures for isolating extremely pure, intact high-titre infectious prions from mammalian brain (Wenborn et al., 2015). Misfolded PrP in these preparations is highly protease-resistant and is assembled into rod-like structures, PrP rods (akin to prion rods identified by Prusiner and colleagues), which faithfully transmit prion strain-specific phenotypes when inoculated into mice (Wenborn et al., 2015). PrP rods are intrinsically infectious in cell culture infectivity assays and form aggregates whose size and number appear to determine the number of infectious units available to cells at inoculation (Terry et al., 2016). Filtration of the rod preparations showed no evidence for the presence of small infectious oligomers of $\mathrm{PrP}^{\mathrm{Sc}}$ and thermal and chemical inactivation profiles of prion infectivity indicated the destruction of the same infectious structures in isolated PrP rod preparations or starting brain homogenate (Terry et al., 2016). Importantly, exploration of the origin of the PrP rods showed no evidence for their artifactual generation during purification as they could be isolated from brain without using detergent and the dimensions and morphology of the rods from crude brain homogenate were not noticeably influenced by variable exposure to protease and detergent (Terry et al., 2016). Differences in the length of propagating infectious $\mathrm{PrP}$ rods in brain (in which the ends of the rod may comprise the infectious surface) can readily explain variance in specific prion infectivity with respect to $\operatorname{Pr} P$ monomers and also account for the widespread distribution of infectious prion particles that is seen when prion-infected brain homogenate is fractionated by sedimentation velocity ultracentrifugation (Prusiner et al., 1987).

\section{INFECTIOUS EX VIVO PrP RODS HAVE UNIQUE STRUCTURAL FEATURES}

Examination of infectious $\operatorname{PrP}$ rods isolated from multiple prion strains by negative-stain electron microscopy (EM), negative-stain electron tomography, cryo-EM and atomic force microscopy (AFM) have recently revealed a common 
three-dimensional architecture (Terry et al., 2016, 2019). Infectious PrP rods are $\sim 20 \mathrm{~nm}$ wide and are composed of two fibers (each with a double helical substructure) separated by a distinct gap of 8-10 $\mathrm{nm}$ in width. AFM showed that the central gap contains irregularly-structured material that appears to be compositionally distinct from the surface of the individual fibers. This finding is consistent with the idea that PrP N-linked glycans in the gap may be contributing to the overall stability of the rod and as a consequence its infectivity (Terry et al., 2016, 2019). The overall architecture of the infectious PrP rods is very distinct to the structure of non-infectious PrP fibrils generated in vitro from recombinant $\mathrm{PrP}$ which comprise long, single fibers ( $10 \mathrm{~nm}$ wide) formed by a double helical arrangement of two protofilaments (Tattum et al., 2006; Terry et al., 2016, 2019; Figure 1).

Notably, because of their helical twist, PrP rods when imaged on a surface alternate between narrower, edge-on and wider, face-on views of the structure. Consequently, the overall architecture of this twisted assembly is often hard to distinguish in EM images, which are two-dimensional density projections. However, the twist of the paired fibers in the rod, as well as a twisted two stranded structure within each fiber, becomes apparent when the three dimensional structure of the assembly is resolved by tomography (Terry et al., 2016). Significantly, visualization of the PrP rods by tomography and the ensuing recognition of their basic architecture (Terry et al., 2016, 2019) now enables the structural features of the PrP rods to be readily seen in most published EM images of SAFs and prion rods from earlier studies, including those from CJD brain (Merz et al., 1984). Collectively, these new data overturn previous dogma and firmly establish ex vivo PrP rods as the authentic infectious prion assembly state that should now be targeted in future high resolution imaging studies.

At present without a high-resolution three-dimensional structure of infectious $\operatorname{PrP}$ rods, the detailed arrangement of secondary structure components of $\operatorname{PrP}$ within the fibers of the rod remains unknown. Knowledge of the structures of alternative single fiber $\mathrm{PrP}$ amyloid fibrils (either generated

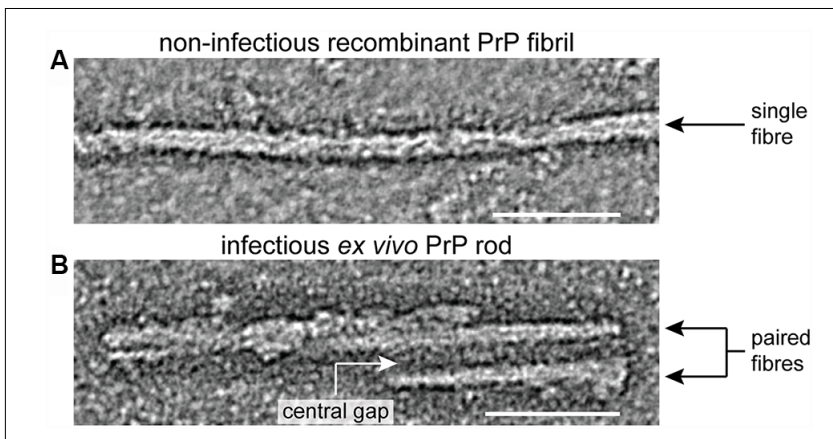

FIGURE 1 | Structural differences between infectious ex vivo PrP rods and non-infectious recombinant prion protein (PrP) fibrils generated in vitro. Panels $(\mathbf{A}, \mathbf{B})$ show sections from negative stain electron tomography reconstructions that were originally published in (Terry et al., 2016), scale bars, $50 \mathrm{~nm}$. Non-infectious recombinant PrP fibrils (A) appear as single fibers $\sim 10 \mathrm{~nm}$ wide comprised of two closely intertwined protofilaments (Tattum et al., 2006; Terry et al., 2016). In contrast infectious ex vivo PrP rods (B) are $\sim 20 \mathrm{~nm}$ wide and are composed of two fibers (each with a double helical substructure) separated by a central gap of $8-10 \mathrm{~nm}$ in width which is filled with irregularly structured material (Terry et al., 2016, 2019).

in vitro or isolated from mice expressing mutant $\mathrm{PrP}$ ) cannot be applied with any certainty to the PrP rods (Terry et al., 2016, 2019). From the various PrP fibrillar structures that have been characterized to date, two major structural models for prions have been proposed; the parallel in-register intermolecular $\beta$-sheet (PIRIBS) architectures and the 4-rung beta solenoid model (Baskakov et al., 2019). Determining whether either of these models applies to infectious PrP rods is now dependent on obtaining their high resolution structure.

While strain-specific structural differences in infectious $\operatorname{PrP}$ rods may become apparent with future application of higher resolution imaging methods (such as cryo-tomography and subtomogram averaging) their basic architecture can now be compared with fibrillar assemblies of other proteins that propagate in other neurodegenerative diseases (Table 1). Based upon the available data the structure of infectious PrP rods can be

TABLE 1 | Studies reporting the structures of fibrillar protein assemblies from patients with various neurodegenerative diseases other than prion diseases.

\begin{tabular}{|c|c|c|c|}
\hline Neurodegenerative disease (assembled protein) & Structural method & Tissue source & Reference \\
\hline Alzheimer's disease (AD; Amyloid- $\beta$ ) & Negative stain EM & Brain from patients with $A D$ & Paravastu et al. (2009) \\
\hline Alzheimer's disease (Amyloid- $\beta$ ) & Negative stain EM & Brain from patients with $A D$ & Lu et al. (2013) \\
\hline Alzheimer's disease (Tau) & Cryo-EM & Brain from patients with $A D$ & Fitzpatrick et al. (2017) \\
\hline Pick's disease (Tau) & Cryo-EM & Brain from patients with Pick's disease & Falcon et al. (2018) \\
\hline Chronic traumatic encephalopathy (CTE; Tau) & Cryo-EM & Brain from patients with CTE & Falcon et al. (2019) \\
\hline $\begin{array}{l}\text { Parkinson's disease/dementia with Lewy bodies } \\
\text { ( } \alpha \text {-synuclein) }\end{array}$ & Negative stain EM & $\begin{array}{l}\text { Brain from patients with dementia with } \\
\text { Lewy bodies }\end{array}$ & Spillantini et al. (1998) \\
\hline Amyotrophic lateral sclerosis (ALS; SOD1) & Negative stain EM & $\begin{array}{l}\text { Spinal cord from patients with familial } \\
\text { ALS }\end{array}$ & Kato et al. $(1997,2000)$ \\
\hline $\begin{array}{l}\text { Frontotemporal lobar degeneration (FTLD-U) and } \\
\text { amyotrophic lateral sclerosis (TDP-43) }\end{array}$ & Negative stain EM & $\begin{array}{l}\text { Brain from patients with FTLD-U and } \\
\text { ALS }\end{array}$ & Lin and Dickson (2008) \\
\hline Frontotemporal lobar degeneration (TDP-43) & Negative stain EM & $\begin{array}{l}\text { Brain from patients with FTLD with } \\
\text { TDP-43 proteinopathy }\end{array}$ & Thorpe et al. (2008) \\
\hline $\begin{array}{l}\text { Amyotrophic lateral sclerosis and frontotemporal lobar } \\
\text { degeneration (TDP-43) }\end{array}$ & Negative stain EM & $\begin{array}{l}\text { Brain from patients with ALS and } \\
\text { FTLD-with TDP- } 43 \text { proteinopathy }\end{array}$ & Nonaka et al. (2013) \\
\hline Frontotemporal lobar degeneration (TDP-43) & Negative stain EM & $\begin{array}{l}\text { Brain from patients with FTLD with } \\
\text { TDP- } 43 \text { proteinopathy }\end{array}$ & Laferrière et al. (2019) \\
\hline
\end{tabular}


readily distinguished from fibrillar structures of tau, amyloid- $\beta$, $\alpha$-synuclein, TDP-43 and SOD1 because none of these possess a prominent central gap region that resembles the PrP rods.

\section{CO-PROPAGATION OF INFECTIOUS PrP RODS AND TRANSMISSIBLE PrP AMYLOID}

Prion-infected transgenic mice expressing mutant GPI-anchorless PrP replicate authentic prions (that are transmissible to wild-type mice) but they also develop intense PrP amyloid plaques in their brain which are not seen in the brain of prion-infected wild-type mice (Chesebro et al., 2005, 2010). Based upon the currently available evidence (summarized in Terry et al., 2019) it appears that prion infection in these mice leads to the propagation of infectious $\mathrm{PrP}$ rods which account for the transmissible prion infectivity and structurally distinct single PrP fibers (10 nm wide; Vázquez-Fernández et al., 2016) which account for the striking PrP amyloid plaque deposits that distinguish these mice.

Importantly, such co-propagation of infectious paired-fiber $\operatorname{PrP}$ rods and distinct single-fiber amyloid PrP assemblies may also be occurring in some inherited prion diseases in particular in patients with GSS disease phenotypes in which amyloid plaques are a prominent neuropathological feature (see Terry et al., 2019). This could readily explain why biochemically-distinct PrP assemblies from GSS patients with the P102L PrP mutation can transmit different phenotypes to experimental mice resulting in either a clinically silent $\operatorname{PrP}$ amyloidosis or a lethal spongiform encephalopathy (Piccardo et al., 2007; Barron et al., 2016; Barron, 2017). Variation in the substructure of infectious $\operatorname{PrP}$ rods or distinct amyloid $\operatorname{PrP}$ fibrils (governed by the specific PrP missense mutation) would be expected to dictate highly specific strain transmission properties via conformational selection (Collinge, 1999, 2016; Collinge and Clarke, 2007; Wadsworth et al., 2010) as has recently been demonstrated for PRNP P102L and A117V mutations (Asante et al., 2009, 2013, 2015). Notably, while patients with different PRNP missense mutations that produce full-length

\section{REFERENCES}

Asante, E. A., Gowland, I., Grimshaw, A., Linehan, J. M., Smidak, M., Houghton, R., et al. (2009). Absence of spontaneous disease and comparative prion susceptibility of transgenic mice expressing mutant human prion proteins. J. Gen. Virol. 90, 546-558. doi: 10.1099/vir.0.007930-0

Asante, E. A., Grimshaw, A., Smidak, M., Jakubcova, T., Tomlinson, A., Jeelani, A., et al. (2015). Transmission properties of human PrP 102L prions challenge the relevance of mouse models of GSS. PLoS Pathog. 11:e1004953. doi: 10.1371/journal.ppat.1004953

Asante, E. A., Linehan, J. M., Smidak, M., Tomlinson, A., Grimshaw, A., Jeelani, A., et al. (2013). Inherited prion disease A117V is not simply a proteinopathy but produces prions transmissible to transgenic mice expressing homologous prion protein. PLoS Pathog. 9:e1003643. doi: 10.1371/journal.ppat.1003643

Banerjee, G., Adams, M. E., Jaunmuktane, Z., Alistair Lammie, G., Turner, B., Wani, M., et al. (2019). Early onset cerebral amyloid angiopathy following childhood exposure to cadaveric dura. Ann. Neurol. 85, 284-290. doi: 10.1002/ana.25407 mutant $\operatorname{PrP}$ (for example P102L) would be expected to be capable of co-propagating both authentic prions (infectious PrP rods) and alternative transmissible PrP amyloid assemblies, patients with different $P R N P$ stop mutations which produce C-terminally truncated PrP devoid of N-linked glycans (for example Y163X; Mead et al., 2013) may only be capable of propagating transmissible $\mathrm{PrP}$ amyloids giving rise to distinct disease phenotypes (Mead and Reilly, 2015).

\section{CONCLUDING REMARKS}

Prion-infected brain contains multiple disease-related $\operatorname{PrP}$ assemblies. Infectious PrP rods comprise authentic prions that generate a lethal transmissible spongiform encephalopathy when inoculated into a susceptible host. Neurotoxicity accompanying the propagation of authentic prions is thought to involve the generation of a distinct toxic PrP species whose steadystate level may determine the rate of neurodegeneration. In some inherited prion diseases transmissible PrP amyloids only may be generated while in others transmissible PrP amyloids may variably co-propagate with authentic prions and act as a major modifier of clinicopathological phenotype. Studying the transmission properties of synthetic prion preparations is complex and experiments should be carefully designed and interpreted in order to differentiate between the generation of authentic lethal prions and transmissible PrP amyloids. At present, propagating fibrillar assemblies of proteins in other neurodegenerative diseases appear to have biological and structural properties that are more closely aligned with transmissible PrP amyloids rather than authentic lethal prions.

\section{AUTHOR CONTRIBUTIONS}

CT and JW wrote the article.

\section{FUNDING}

This work was funded by the UK Medical Research Council (award MC_UU_00024/5).
Barron, R. M. (2017). Infectious prions and proteinopathies. Prion 11, 40-47. doi: 10.1080/19336896.2017.1283464

Barron, R. M., King, D., Jeffrey, M., McGovern, G., Agarwal, S., Gill, A. C., et al. (2016). PrP aggregation can be seeded by pre-formed recombinant PrP amyloid fibrils without the replication of infectious prions. Acta Neuropathol. 132, 611-624. doi: 10.1007/s00401-016-1594-5

Barry, R. A., McKinley, M. P., Bendheim, P. E., Lewis, G. K., DeArmond, S. J., and Prusiner, S. B. (1985). Antibodies to the scrapie protein decorate prion rods. J. Immunol. 135, 603-613.

Baskakov, I. V., Caughey, B., Requena, J. R., Sevillano, A. M., Surewicz, W. K., and Wille, H. (2019). The prion 2018 round tables (I): the structure of $\mathrm{PrP}^{\mathrm{Sc}}$. Prion 13, 46-52. doi: 10.1080/19336896.2019.15 69450

Benestad, S. L., and Telling, G. C. (2018). Chronic wasting disease: an evolving prion disease of cervids. Handb. Clin. Neurol. 153, 135-151. doi: 10.1016/b9780-444-63945-5.00008-8

Cali, I., Cohen, M. L., Haik, S., Parchi, P., Giaccone, G., Collins, S. J., et al. (2018). Iatrogenic Creutzfeldt-Jakob disease with amyloid- $\beta$ pathology: an 
international study. Acta Neuropathol. Commun. 6:5. doi: 10.1186/s40478-0170503-z

Caughey, B., Raymond, G. J., and Bessen, R. A. (1998). Strain-dependent differences in $\beta$-sheet conformations of abnormal prion protein. J. Biol. Chem. 273, 32230-32235. doi: 10.1074/jbc.273.48.32230

Chesebro, B., Race, B., Meade-White, K., LaCasse, R., Race, R., Klingeborn, M., et al. (2010). Fatal transmissible amyloid encephalopathy: a new type of prion disease associated with lack of prion protein membrane anchoring. PLoS Pathog. 6:e1000800. doi: 10.1371/journal.ppat.1000800

Chesebro, B., Trifilo, M., Race, R., Meade-White, K., Teng, C., LaCasse, R., et al. (2005). Anchorless prion protein results in infectious amyloid disease without clinical scrapie. Science 308, 1435-1439. doi: 10.1126/science.1110837

Collinge, J. (1999). Variant Creutzfeldt-Jakob disease. Lancet 354, 317-323. doi: 10.1016/S0140-6736(99)05128-4

Collinge, J. (2001). Prion diseases of humans and animals: their causes and molecular basis. Annu. Rev. Neurosci. 24, 519-550. doi: 10.1146/annurev.neuro. 24.1.519

Collinge, J. (2016). Mammalian prions and their wider relevance in neurodegenerative diseases. Nature 539, 217-226. doi: 10.1038/nature20415

Collinge, J., and Clarke, A. (2007). A general model of prion strains and their pathogenicity. Science 318, 930-936. doi: 10.1126/science.1138718

Condello, C., Lemmin, T., Stöhr, J., Nick, M., Wu, Y., Maxwell, A. M., et al. (2018). Structural heterogeneity and intersubject variability of $A \beta$ in familial and sporadic Alzheimer's disease. Proc. Natl. Acad. Sci. U S A 115, E782-E791. doi: 10.1073/pnas. 1714966115

Cronier, S., Gros, N., Tattum, M. H., Jackson, G. S., Clarke, A. R., Collinge, J., et al. (2008). Detection and characterization of proteinase K-sensitive disease-related prion protein with thermolysin. Biochem. J. 416, 297-305. doi: $10.1042 /$ bj20081235

D'Castro, L., Wenborn, A., Gros, N., Joiner, S., Cronier, S., Collinge, J., et al. (2010). Isolation of proteinase $\mathrm{k}$-sensitive prions using pronase e and phosphotungstic acid. PLoS One 5:e15679. doi: 10.1371/journal.pone.0015679

DeArmond, S. J., McKinley, M. P., Barry, R. A., Braunfeld, M. B., McColloch, J. R., and Prusiner, S. B. (1985). Identification of prion amyloid filaments in scrapieinfected brain. Cell 41, 221-235. doi: 10.1016/0092-8674(85)90076-5

Diaz-Espinoza, R., and Soto, C. (2012). High-resolution structure of infectious prion protein: the final frontier. Nat. Struct. Mol. Biol. 19, 370-377. doi: $10.1038 / \mathrm{nsmb} .2266$

Duyckaerts, C., Clavaguera, F., and Potier, M. C. (2019). The prion-like propagation hypothesis in Alzheimer's and Parkinson's disease. Curr. Opin. Neurol. 32, 266-271. doi: 10.1097/WCO.0000000000000672

Eisenberg, D. S., and Sawaya, M. R. (2017). Structural studies of amyloid proteins at the molecular level. Annu. Rev. Biochem. 86, 69-95. doi: 10.1146/annurevbiochem-061516-045104

Eraña, H. (2019). The Prion 2018 round tables (II): A $\beta$, tau, $\alpha$-synuclein. . . are they prions, prion-like proteins, or what? Prion 13, 41-45. doi: 10.1080/19336896. 2019.1569451

Falcon, B., Zhang, W., Murzin, A. G., Murshudov, G., Garringer, H. J., Vidal, R., et al. (2018). Structures of filaments from Pick's disease reveal a novel tau protein fold. Nature 561, 137-140. doi: 10.1038/s41586-018-0454-y

Falcon, B., Zivanov, J., Zhang, W., Murzin, A. G., Garringer, H. J., Vidal, R., et al. (2019). Novel tau filament fold in chronic traumatic encephalopathy encloses hydrophobic molecules. Nature 568, 420-423. doi: 10.1038/s41586-019-1026-5

Fitzpatrick, A. W. P., Falcon, B., He, S., Murzin, A. G., Murshudov, G., Garringer, H. J., et al. (2017). Cryo-EM structures of tau filaments from Alzheimer's disease. Nature 547, 185-190. doi: 10.1038/nature23002

Frontzek, K., Lutz, M. I., Aguzzi, A., Kovacs, G. G., and Budka, H. (2016). Amyloid- $\beta$ pathology and cerebral amyloid angiopathy are frequent in iatrogenic Creutzfeldt-Jakob disease after dural grafting. Swiss Med. Wkly. 146:w14287. doi: 10.4414/smw.2016.14287

Goedert, M. (2015). Neurodegeneration. Alzheimer's and Parkinson's diseases: the prion concept in relation to assembled $\mathrm{A} \beta$, tau, and $\alpha$-synuclein. Science 349:1255555. doi: 10.1126/science. 1255555

Greenlee, J. J., and Greenlee, M. H. (2015). The transmissible spongiform encephalopathies of livestock. ILAR J. 56, 7-25. doi: 10.1093/ilar/ilv008

Haïk, S., and Brandel, J. P. (2014). Infectious prion diseases in humans: cannibalism, iatrogenicity and zoonoses. Infect. Genet. Evol. 26, 303-312. doi: 10.1016/j.meegid.2014.06.010
Iadanza, M. G., Jackson, M. P., Hewitt, E. W., Ranson, N. A., and Radford, S. E. (2018). A new era for understanding amyloid structures and disease. Nat. Rev. Mol. Cell Biol. 19, 755-773. doi: 10.1038/s41580-018-0060-8

Jaunmuktane, Z., Mead, S., Ellis, M., Wadsworth, J. D., Nicoll, A. J., Kenny, J., et al. (2015). Evidence for human transmission of amyloid- $\beta$ pathology and cerebral amyloid angiopathy. Nature 525, 247-250. doi: 10.1038/nature 15369

Kara, E., Marks, J. D., and Aguzzi, A. (2018). Toxic protein spread in neurodegeneration: reality versus fantasy. Trends Mol. Med. 24, 1007-1020. doi: 10.1016/j.molmed.2018.09.004

Kato, S., Hayashi, H., Nakashima, K., Nanba, E., Kato, M., Hirano, A., et al. (1997). Pathological characterization of astrocytic hyaline inclusions in familial amyotrophic lateral sclerosis. Am. J. Pathol. 151, 611-620.

Kato, S., Takikawa, M., Nakashima, K., Hirano, A., Cleveland, D. W., Kusaka, H., et al. (2000). New consensus research on neuropathological aspects of familial amyotrophic lateral sclerosis with superoxide dismutase 1 (SOD1) gene mutations: inclusions containing SOD1 in neurons and astrocytes. Amyotroph. Lateral. Scler. Other Motor Neuron Disord. 1, 163-184. doi: 10.1080/14660820050515160

Klöhn, P., Stoltze, L., Flechsig, E., Enari, M., and Weissmann, C. (2003). A quantitative, highly sensitive cell-based infectivity assay for mouse scrapie prions. Proc. Natl. Acad. Sci. U S A 100, 11666-11671. doi: 10.1073/pnas. 1834432100

Laferrière, F., Maniecka, Z., Pérez-Berlanga, M., Hruska-Plochan, M., Gilhespy, L., Hock, E. M., et al. (2019). TDP-43 extracted from frontotemporal lobar degeneration subject brains displays distinct aggregate assemblies and neurotoxic effects reflecting disease progression rates. Nat. Neurosci. 22, 65-77. doi: 10.1038/s41593-018-0294-y

Lin, W. L., and Dickson, D. W. (2008). Ultrastructural localization of TDP-43 in filamentous neuronal inclusions in various neurodegenerative diseases. Acta Neuropathol. 116, 205-213. doi: 10.1007/s00401-008-0408-9

Lu, J. X., Qiang, W., Yau, W. M., Schwieters, C. D., Meredith, S. C., and Tycko, R. (2013). Molecular structure of $\beta$-amyloid fibrils in Alzheimer's disease brain tissue. Cell 154, 1257-1268. doi: 10.1016/j.cell.2013.08.035

Mahal, S. P., Baker, C. A., Demczyk, C. A., Smith, E. W., Julius, C., and Weissmann, C. (2007). Prion strain discrimination in cell culture: the cell panel assay. Proc. Natl. Acad. Sci. U S A 104, 20908-20913. doi: 10.1073/pnas. 0710054104

McKinley, M. P., Meyer, R. K., Kenaga, L., Rahbar, F., Cotter, R., Serban, A., et al. (1991). Scrapie prion rod formation in vitro requires both detergent extraction and limited proteolysis. J. Virol. 65, 1340-1351.

Mead, S., and Reilly, M. M. (2015). A new prion disease: relationship with central and peripheral amyloidoses. Nat. Rev. Neurol. 11, 90-97. doi: 10.1038/nrneurol. 2014.263

Mead, S., Gandhi, S., Beck, J., Caine, D., Gallujipali, D., Carswell, C., et al. (2013). A novel prion disease associated with diarrhea and autonomic neuropathy. $N$. Engl. J. Med. 369, 1904-1914. doi: 10.1056/NEJMoa1214747

Merz, P. A., Rohwer, R. G., Kascsak, R., Wisniewski, H. M., Somerville, R. A., Gibbs, C. J. Jr., et al. (1984). Infection-specific particle from the unconventional slow virus diseases. Science 225, 437-440. doi: 10.1126/science.6377496

Merz, P. A., Somerville, R. A., Wisniewski, H. M., and Iqbal, K. (1981). Abnormal fibrils from scrapie-infected brain. Acta Neuropathol. 54, 63-74. doi: $10.1007 /$ bf00691333

Meyer, R. K., McKinley, M. P., Bowman, K., Braunfeld, M. B., Barry, R. A., and Prusiner, S. B. (1986). Separation and properties of cellular and scrapie prion proteins. Proc. Natl. Acad. Sci. U S A 83, 2310-2314. doi: 10.1073/pnas.83. 8.2310

Moudjou, M., Chapuis, J., Mekrouti, M., Reine, F., Herzog, L., Sibille, P., et al. (2016). Glycoform-independent prion conversion by highly efficient, cell-based, protein misfolding cyclic amplification. Sci. Rep. 6:29116. doi: 10.1038/srep29116

Nonaka, T., Masuda-Suzukake, M., Arai, T., Hasegawa, Y., Akatsu, H., Obi, T., et al. (2013). Prion-like properties of pathological TDP-43 aggregates from diseased brains. Cell Rep. 4, 124-134. doi: 10.1016/j.celrep.2013.06.007

Pan, K. M., Baldwin, M. A., Nguyen, J., Gasset, M., Serban, A., Groth, D., et al. (1993). Conversion of $\alpha$-helices into $\beta$-sheets features in the formation of the scrapie prion proteins. Proc. Natl. Acad. Sci. U S A 90, 10962-10966. doi: 10.1073 /pnas. 90.23 .10962 
Paravastu, A. K., Qahwash, I., Leapman, R. D., Meredith, S. C., and Tycko, R. (2009). Seeded growth of $\beta$-amyloid fibrils from Alzheimer's brain-derived fibrils produces a distinct fibril structure. Proc. Natl. Acad. Sci. U S A 106, 7443-7448. doi: 10.1073/pnas.0812033106

Peng, C., Gathagan, R. J., and Lee, V. M. (2018). Distinct $\alpha$-synuclein strains and implications for heterogeneity among $\alpha$-synucleinopathies. Neurobiol. Dis. 109, 209-218. doi: 10.1016/j.nbd.2017.07.018

Piccardo, P., Manson, J. C., King, D., Ghetti, B., and Barron, R. M. (2007). Accumulation of prion protein in the brain that is not associated with transmissible disease. Proc. Natl. Acad. Sci. U S A 104, 4712-4717. doi: 10.1073/pnas.0609241104

Prusiner, S. B. (1987). Prions causing degenerative neurological diseases. Annu. Rev. Med. 38, 381-398. doi: 10.1146/annurev.me.38.020187.002121

Prusiner, S. B. (1991). Molecular biology of prion diseases. Science 252, 1515-1522. doi: $10.1126 /$ science. 1675487

Prusiner, S. B. (1998). Prions. Proc. Natl. Acad. Sci. U S A 95, 13363-13383. doi: $10.1073 /$ pnas. 95.23 .13363

Prusiner, S. B. (2013). Biology and genetics of prions causing neurodegeneration. Annu. Rev. Genet. 47, 601-623. doi: 10.1146/annurev-genet-110711-155524

Prusiner, S. B., Bowman, K., and Groth, D. F. (1987). "Purification of scrapie prions," in Prions: Novel Infectious Pathogens Causing Scrapie and CreutzfeldtJakob Disease, eds S. B. Prusiner and M. P. McKinley (San Diego, CA: Academic Press), 149-171.

Prusiner, S. B., McKinley, M. P., Bowman, K., Bolton, D. C., Bendheim, P. E., Groth, D. F., et al. (1983). Scrapie prions aggregate to form amyloid-like birefringent rods. Cell 35, 349-358. doi: 10.1016/0092-8674(83)90168-x

Purro, S. A., Farrow, M. A., Linehan, J., Nazari, T., Thomas, D. X., Chen, Z., et al. (2018). Transmission of amyloid- $\beta$ protein pathology from cadaveric pituitary growth hormone. Nature 564, 415-419. doi: 10.1038/s41586-018-0790-y

Qiang, W., Yau, W. M., Lu, J. X., Collinge, J., and Tycko, R. (2017). Structural variation in amyloid- $\beta$ fibrils from Alzheimer's disease clinical subtypes. Nature 541, 217-221. doi: 10.1038/nature20814

Requena, J. R., and Wille, H. (2014). The structure of the infectious prion protein: experimental data and molecular models. Prion 8, 60-66. doi: 10.4161/pri. 28368

Riesner, D. (2003). Biochemistry and structure of $\operatorname{PrP}^{\mathrm{C}}$ and $\operatorname{PrP}^{\mathrm{Sc}}$. Br. Med. Bull. 66, 21-33. doi: 10.1093/bmb/66.1.21

Ritchie, D. L., Adlard, P., Peden, A. H., Lowrie, S., Le Grice, M., Burns, K., et al. (2017). Amyloid- $\beta$ accumulation in the CNS in human growth hormone recipients in the UK. Acta Neuropathol. 134, 221-240. doi: 10.1007/s00401-0171703-0

Rodriguez, J. A., Jiang, L., and Eisenberg, D. S. (2017). Toward the atomic structure of PrPSc. Cold Spring Harb. Perspect. Biol 9:a031336. doi: 10.1101/cshperspect. a031336

Rossi, M., Baiardi, S., and Parchi, P. (2019). Understanding prion strains: evidence from studies of the disease forms affecting humans. Viruses 11:E309. doi: $10.3390 / \mathrm{v} 11040309$

Safar, J. G., Geschwind, M. D., Deering, C., Didorenko, S., Sattavat, M., Sanchez, H., et al. (2005). Diagnosis of human prion disease. Proc. Natl. Acad. Sci. U S A 102, 3501-3506. doi: 10.1073/pnas.0409651102

Safar, J., Wille, H., Itri, V., Groth, D., Serban, H., Torchia, M., et al. (1998). Eight prion strains have $\operatorname{PrP}^{S c}$ molecules with different conformations. Nat. Med. 4 , 1157-1165. doi: 10.1038/2654

Sandberg, M. K., Al Doujaily, H., Sharps, B., Clarke, A. R., and Collinge, J. (2011). Prion propagation and toxicity in vivo occur in two distinct mechanistic phases. Nature 470, 540-542. doi: 10.1038/nature09768

Sandberg, M. K., Al Doujaily, H., Sharps, B., De Oliveira, M. W., Schmidt, C., Richard-Londt, A., et al. (2014). Prion neuropathology follows the accumulation of alternate prion protein isoforms after infective titre has peaked. Nat. Commun. 5:4347. doi: 10.1038/ncomms5347

Scheckel, C., and Aguzzi, A. (2018). Prions, prionoids and protein misfolding disorders. Nat. Rev. Genet. 19, 405-418. doi: 10.1038/s41576-018-0011-4

Schmidt, C., Fizet, J., Properzi, F., Batchelor, M., Sandberg, M. K., Edgeworth, J. A., et al. (2015). A systematic investigation of production of synthetic prions from recombinant prion protein. Open Biol. 5:150165. doi: 10.1098/rsob.150165

Silveira, J. R., Raymond, G. J., Hughson, A. G., Race, R. E., Sim, V. L., Hayes, S. F., et al. (2005). The most infectious prion protein particles. Nature 437, 257-261. doi: $10.1038 /$ nature03989
Sim, V. L., and Caughey, B. (2009). Ultrastructures and strain comparison of under-glycosylated scrapie prion fibrils. Neurobiol. Aging 30, 2031-2042. doi: 10.1016/j.neurobiolaging.2008.02.016

Spillantini, M. G., Crowther, R. A., Jakes, R., Hasegawa, M., and Goedert, M. (1998). $\alpha$-synuclein in filamentous inclusions of Lewy bodies from Parkinson's disease and dementia with lewy bodies. Proc. Natl. Acad. Sci. U S A 95, 6469-6473. doi: 10.1073/pnas.95.11.6469

Tattum, M. H., Cohen-Krausz, S., Thumanu, K., Wharton, C. W., KhaliliShirazi, A., Jackson, G. S., et al. (2006). Elongated oligomers assemble into mammalian PrP amyloid fibrils. J. Mol. Biol. 357, 975-985. doi: 10.1016/j.jmb. 2006.01.052

Terry, C., Harniman, R. L., Sells, J., Wenborn, A., Joiner, S., Saibil, H. R., et al. (2019). Structural features distinguishing infectious ex vivo mammalian prions from non-infectious fibrillar assemblies generated in vitro. Sci. Rep. 9:376. doi: 10.1038/s41598-018-36700-w

Terry, C., Wenborn, A., Gros, N., Sells, J., Joiner, S., Hosszu, L. L., et al. (2016). Ex vivo mammalian prions are formed of paired double helical prion protein fibrils. Open Biol. 6:160035. doi: 10.1098/rsob.160035

Thorpe, J. R., Tang, H., Atherton, J., and Cairns, N. J. (2008). Fine structural analysis of the neuronal inclusions of frontotemporal lobar degeneration with TDP-43 proteinopathy. J. Neural Transm. 115, 1661-1671. doi: 10.1007/s00702-008-0137-1

Tixador, P., Herzog, L., Reine, F., Jaumain, E., Chapuis, J., Le Dur, A., et al. (2010). The physical relationship between infectivity and prion protein aggregates is strain-dependent. PLoS Pathog. 6:e1000859. doi: 10.1371/journal.ppat.10 00859

Vaquer-Alicea, J., and Diamond, M. I. (2019). Propagation of protein aggregation in neurodegenerative diseases. Annu. Rev. Biochem. 88, 785-810. doi: 10.1146/annurev-biochem-061516-045049

Vázquez-Fernández, E., Vos, M. R., Afanasyev, P., Cebey, L., Sevillano, A. M., Vidal, E., et al. (2016). The structural architecture of an infectious mammalian prion using electron cryomicroscopy. PLoS Pathog. 12:e1005835. doi: 10.1371/journal.ppat.1005835

Vázquez-Fernández, E., Young, H. S., Requena, J. R., and Wille, H. (2017). The structure of mammalian prions and their aggregates. Int. Rev. Cell Mol. Biol. 329, 277-301. doi: 10.1016/bs.ircmb.2016.08.013

Wadsworth, J. D., Asante, E. A., and Collinge, J. (2010). Review; contribution of transgenic models to understanding human prion disease. Neuropathol. Appl. Neurobiol. 36, 576-597. doi: 10.1111/j.1365-2990.2010.01129.x

Wadsworth, J. D., and Collinge, J. (2011). Molecular pathology of human prion disease. Acta Neuropathol. 121, 69-77. doi: 10.1007/s00401-010-0735-5

Walker, L. C. (2016). Proteopathic strains and the heterogeneity of neurodegenerative diseases. Аnnu. Rev. Genet. 50, 329-346. doi: 10.1146/annurev-genet-120215-034943

Wenborn, A., Terry, C., Gros, N., Joiner, S., D’Castro, L., Panico, S., et al. (2015). A novel and rapid method for obtaining high titre intact prion strains from mammalian brain. Sci. Rep. 5:10062. doi: 10.1038/srep10062

Wille, H., Bian, W., McDonald, M., Kendall, A., Colby, D. W., Bloch, L., et al. (2009). Natural and synthetic prion structure from X-ray fiber diffraction. Proc. Natl. Acad. Sci. U S A 106, 16990-16995. doi: 10.1073/pnas.09090 06106

Wüthrich, K., and Riek, R. (2001). Three-dimensional structures of prion proteins. Adv. Protein Chem. 57, 55-82. doi: 10.1016/s0065-3233(01)57018-7

Conflict of Interest Statement: JW is a shareholder of D-Gen Limited, an academic spin-out company working in the field of prion disease diagnosis, decontamination, and therapeutics.

The remaining author declares that the research was conducted in the absence of any commercial or financial relationships that could be construed as a potential conflict of interest.

Copyright (๑) 2019 Terry and Wadsworth. This is an open-access article distributed under the terms of the Creative Commons Attribution License (CC BY). The use, distribution or reproduction in other forums is permitted, provided the original author(s) and the copyright owner(s) are credited and that the original publication in this journal is cited, in accordance with accepted academic practice. No use, distribution or reproduction is permitted which does not comply with these terms. 